\title{
A model to design effective Production Improvement Programs
}

\author{
T. Bautista* ${ }^{1}$, E. M. López-Ortega ${ }^{1}$, J. Zubieta ${ }^{2}$, S. Macías ${ }^{3}$ \\ ${ }^{1}$ Instituto de Ingeniería, UNAM, Ciudad Universitaria, \\ Circuito Escolar S/N; Coyoacán, C.P. 04510, México, D.F. \\ ${ }^{2}$ Instituto de Investigaciones Sociales, \\ UNAM. Ciudad Universitaria, Circuito Mario de la Cueva S/N; \\ Coyoacán, C.P. 04510, México, D.F. \\ ${ }^{3}$ Comité Nacional de Productividad e Innovación Tecnológica, \\ A. C., Manuel Ma. Contreras 133, Col. Cuauhtémoc, C.P. 06500, México, D.F. \\ *tbag_18@hotmail.com Tel.: +52 56233500 Ext. 1211.
}

\begin{abstract}
The objective of this paper is to present a model to design effective Production Improvement Programs (PIP) in order to contribute in the solution of the problematic situations generally faced by the Mexican manufacturing micro, small and mediumsized enterprises (M-SME). In this proposal, we imply that facilitating their development is a natural way to improve their performance, especially in terms of productive efficiency. The study picked up empirical evidence from the Processes Reengineering Workshop (PRW), one of the leading services of the National Committee of Productivity and Technological Innovation (NCPTI) which is considered a Mexican successful case. We show through a comparative analysis that it is possible to have better programs when they follow a continuous improvement process involving the owner of the firm and workforce participation. Furthermore, we suggest a series of methods for planning, structuring and improvement according to the imitative, tacit and qualitative M-SME specific competence.
\end{abstract}

Keywords: growth, Productive Improvement Programs, M-SME, classification, Ministry of the Economy, Mexico.

\section{RESUMEN}

El objetivo de este artículo es presentar un modelo de diseño de Programas Efectivos de Mejora de la Producción, a fin de contribuir en la solución de la situación problemática que generalmente enfrenta el sector de la micro, pequeña y mediana empresa manufacturera mexicana. Suponemos que facilitar el desarrollo es una manera natural para mejorar el desempeño, especialmente en términos de la eficiencia productiva. El estudio recoge evidencias empíricas provenientes del Taller de Reingeniería de Procesos (PRW, por sus siglas en inglés) del Comité Nacional de Productividad e Innovación Tecnológica (NCPTI, por sus siglas en inglés), que es considerado un caso de éxito mexicano. A través de un análisis comparativo mostramos que es posible contar con mejores PIP cuando se encuentran sujetos a procesos de mejora continua, involucrando al empresario y a los trabajadores en la identificación y la solución de problemas internos de las organizaciones. Al tiempo, recomendamos una serie de métodos de planeación, estructuración y de mejora que pudieran ser adoptados por empresas que en este artículo se han denominado imitativas, tácitas y cualitativas.

\section{Introduction}

At the end of the last decade, according to the Intersecretarial Commission of Industrial Political (ICIP) [1] and Nexus [2], Mexican Production Improvement Programs mainly faced two problems: the lack of economic resources to meet the requirements of a greater number of firms (around three million Mexican firms) and the unsuitable design to satisfy the productive needs of M-SME.

The budget allocated to the programs shows that the federal government has focused on the first problem. In the year 2002, PIP received 2.5 billion pesos, and in the year 2005 their budget increased to 4.5 billion pesos. This change has allowed for an increase in firms that benefit from the program. 
When it comes to strategies dedicated to find solutions to the unsuitable design of the PIP, they are circumscribed or almost nonexistent. One recorded evidence of this situation shows that in 1999 Nexus proposed that, in order to design PIP, it was necessary to follow a process constituted by the following: design/redesign, planning, implementation, and evaluation. This would allow for strategies to be in continuous improvement according to the internal problems faced by $\mathrm{M}$ SME. In the year 2003, ICIP claimed that PIP were not aligned according to the productive needs of the national M-SME. In other latitudes, Huang [3] and the United Nations Industrial Development Organization [4] have made the same recommendation. However, at the present time, their models have not been presented.

In the last five years, the Mexican Ministry of the Economy (ME) has basically evaluated the operation of PIP and has failed to measure their effectiveness on the solution of internal problems of M-SME. Evidence of this behavior is shown in the operation rules for every program which establish evaluation procedures. Therefore, there is no evidence that programs have advanced in the solution of production needs.

Another suggestion in reference to the design of PIP is the consideration of their differences amongst them as an additional element to increase their effectiveness. The size of the firm has been the main suggested criteria for this purpose. For example, in the year 2000, ME proposed that the design of programs should be differentiated by the number of employees and by the time the firms have remained in the market.

According to Hernández [5], proposals made by the current decision makers of ME are almost identical to those made in the past. For instance, it has been said that there is a need for differentiated programs according to the size of the firm, the segment and sector, making it necessary to classify firms into Gazelle and Tractor. However, this taxonomy does not offer any arguments to set these outlines.

Therefore, the purpose of this paper is to present a model to design differentiated PIP according to the general structure analysis of RPW and the findings obtained through the information analysis of 3,545 interventions corresponding to the same number of firms benefited by this workshop from 1998 to 2002.

The phases of this method include a diagnosis, in order to identify the productive problems of $\mathrm{M}$ $\mathrm{SME}$, an evaluation of the alternatives, design and implementation, and an evaluation of results. Distinctive features of the model include the expertise of the owner-manager and the workforce and the use of a participative technique to evaluate the D-PIP effectiveness and to obtain a process of continuous improvement.

\section{A model to design effective D-PIP}

The model proposed aims to design D-PIP taking into consideration the level of growth of the firm, as shown in Figure 1 . It fosters continuous strengthening of the organization and production of M-SME. By identifying their internal problems and, therefore, solving them, M-SME will obtain expertise according to their own resources. As a result, the program services guide and advise the problems solutions. It is important to note that the model is focused on designing programs rather than creating intervention methods. 


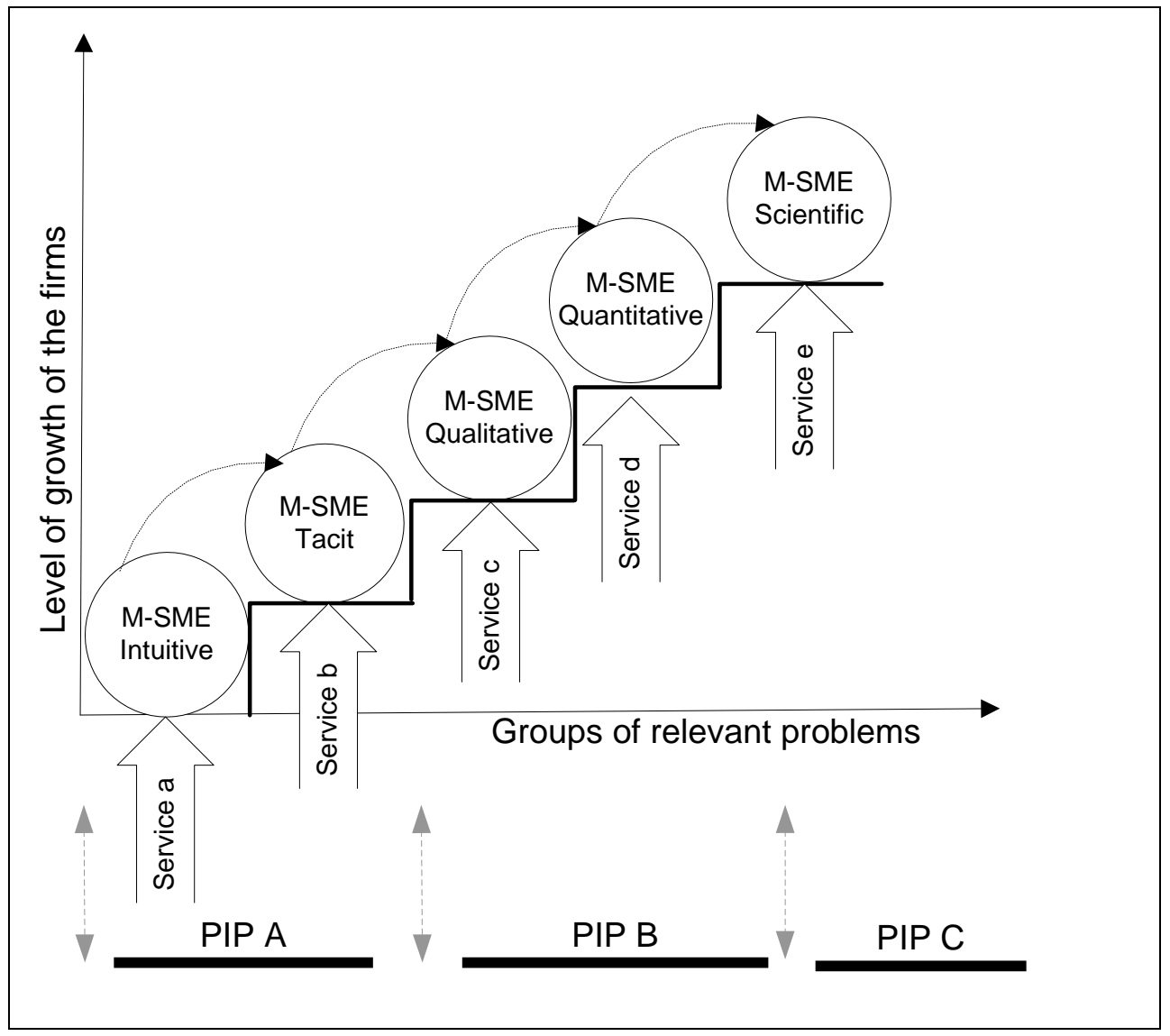

Figure 1. General idea to design D-PIP.

The model is composed of four stages: 1) Diagnosis: to identify the M-SME productive problems, here we must recognize the relevant problems for every group of M-SME; 2) Evaluation of alternatives: in this phase, experts propose possible solutions and evaluate their impact; 3) Design and implementation: where the decision makers choose the services and designers plan the necessary resources to implement every one of such services, and 4) Evaluation of results: measuring the D-PIP efficiency and efficacy. See Figure 2.

\subsection{Diagnosis to identify M-SME productive problems}

The process for this stage is shown in Figure 3. Its objective is to identify the M-SME relevant productive problems and to cluster them in order to classify M-SME.

There are basically two inputs: the expertise due to operation of PIP and expertise due to operation of M-SME. The first one considers the participation of decision makers, managers, consultants and planners while the second one refers to the owner-manager and workers involved in the production processes. 


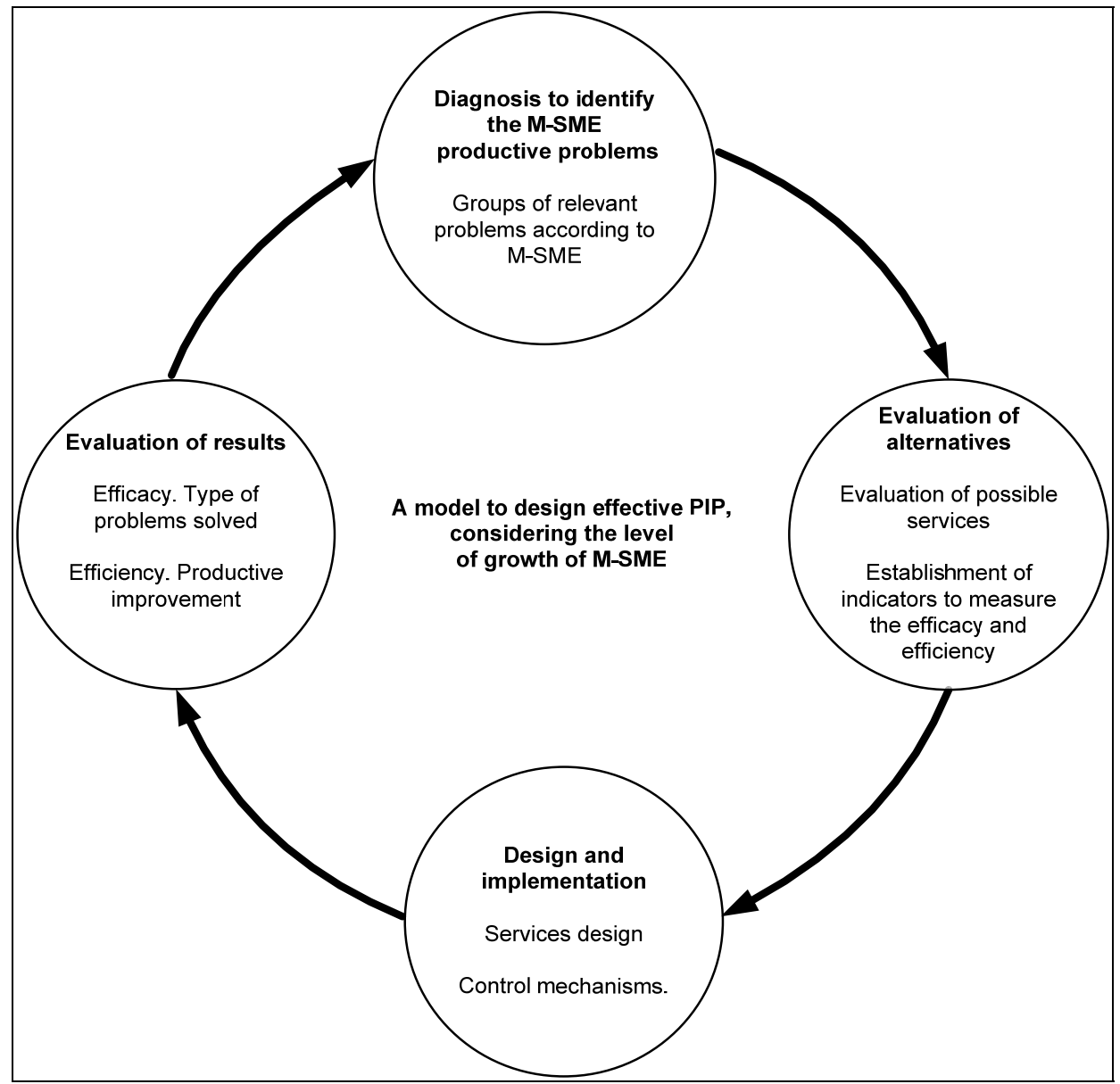

Figure 2. A model to design D-PIP.

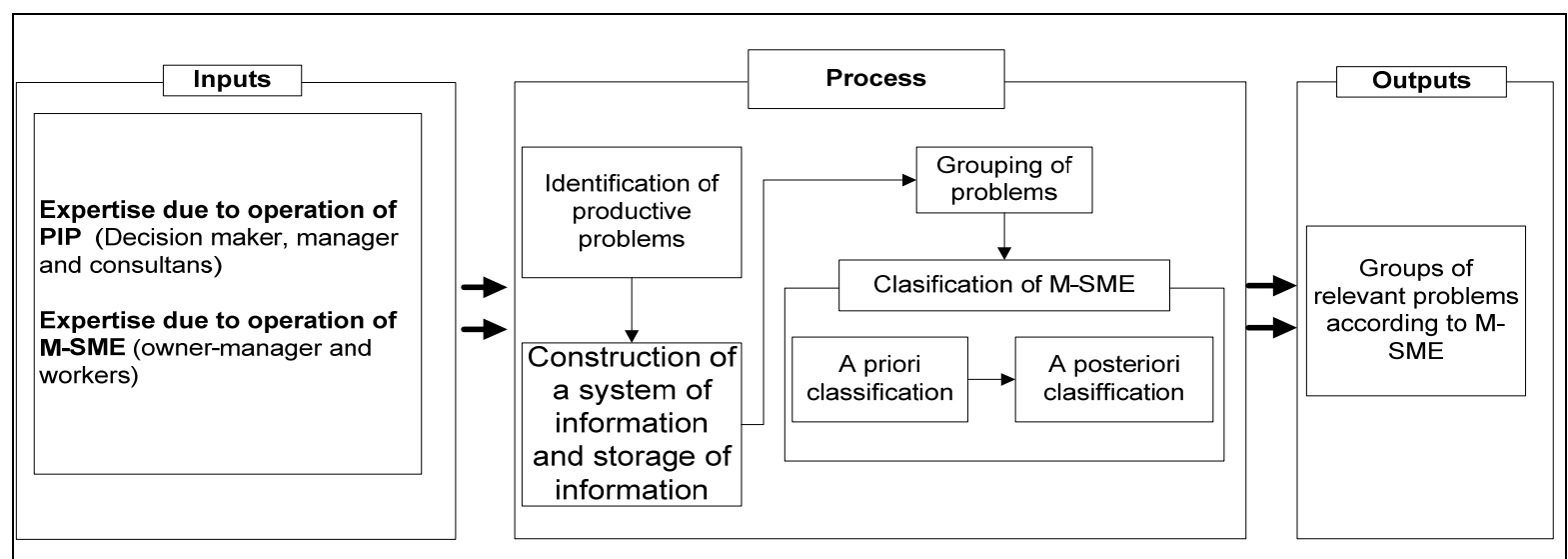

Figure 3. M-SME: diagnosis and classification. 
Techniques recommended to gather information about productive problems are Delphi, nominal group techniques, brainstorming, focus group and interviews. All of them allow interchange of ideas and agreement between participants. When it is not possible to get information with these techniques, which need a high level of participation, it is possible to identify the problems using information gathered by programs from last experiences. This will only be possible if such programs, through their services, include diagnostic stages.

In order to do a systematic analysis of the productive problems, it is necessary to design and develop information systems thus facilitating the use of multivariate analysis. For example, the cluster analysis, where the objective is to classify a set of objects or variables according to certain similitude.
The classification of firms is composed of two steps: an a priori and an a posteriori classification. The first one consists in associating the group or groups of problems to a specific category of $M$ SME. In this stage, the participation of consultants is important since they are working narrowly with this type of firms and know their behavior.

The a posteriori classification consists in validating, through statistical techniques, the a priori classification. A discriminate analysis is a useful technique to accept or reject the a priori classification.

\subsection{Evaluation of alternatives}

The objective of this stage is to suggest alternatives for solving problems for every group of M-SME, the measurement of their impact and election of the most fitting one. Figure 4 shows the process to achieve this goal.

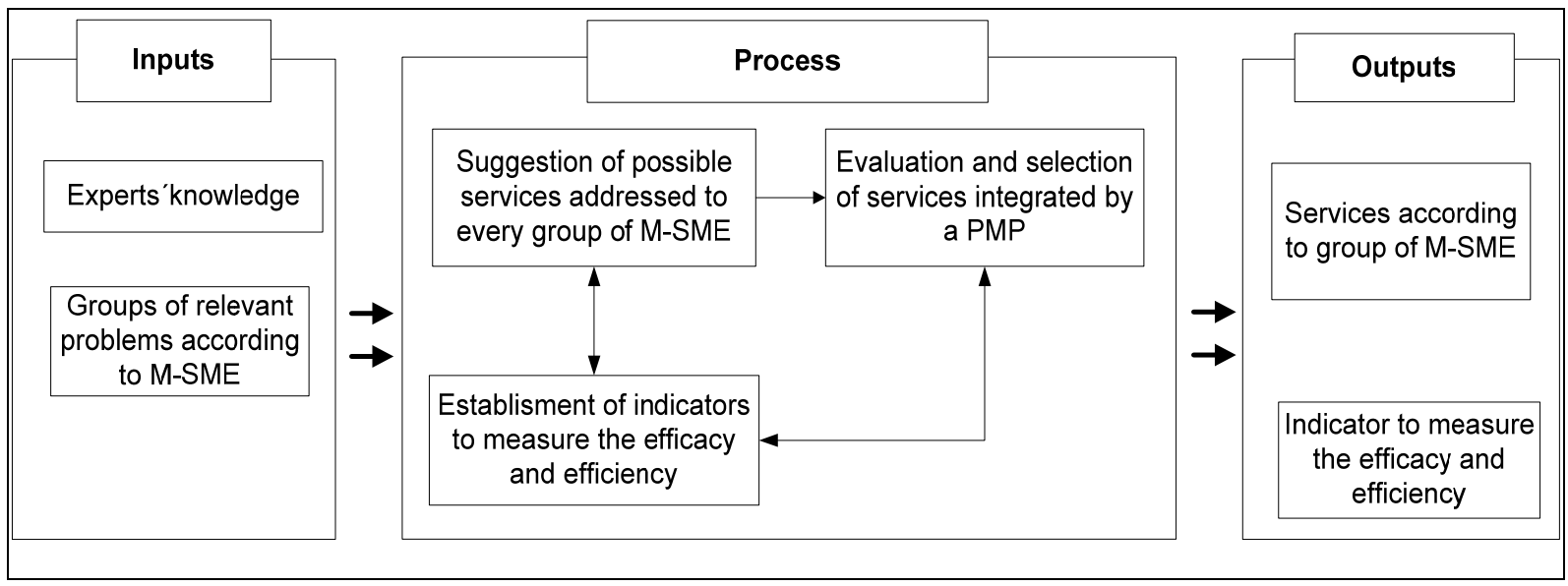

Figure 4. Evaluation of solution alternatives. 
In this section, the displacement analysis of the mechanism under study is presented. The inverse position analysis (IPA) consists of finding the generalized coordinates of the parallel manipulator given the pose, position and orientation of the moving platform with respect to the fixed platform whereas the forward position analysis (FPA) consists of finding the pose of the

Services are production techniques such as Pullbased Manufacturing, Push-based Manufacturing, and Kanban, among others. Such techniques may be transferred to be used through the following category of services.

- Training. Courses addressed to the ownermanager, workers or both, where productive improvement topics are taught by experts, who do not have a direct relationship with the firm.

- Consultancy and technical assistance. It is carried out when the firms require help to identify problems and, based on this, make recommendations on specific solutions. In these services, the consultant generally performs some activities to identify problems and suggest solutions. The owner-manager just executes the suggestions of the consultant.

-Integral consultancy. It is composed by the diagnosis, solution design, implementation and evaluation. Substantial participation of the organization's stakeholders is necessary to identify and solve problems.

The indicators have to be addressed to measure the benefits generated by every program service, specifically, the efficacy of the services and efficiency of M-SME. The former is related with the contribution to solve problems and the level of growth of M-SME. The latter has to be reflected by the productive improvement that M-SME achieves due to the service intervention.

First, it would be possible to elaborate a checklist of problems; then, gathering information from program services in every intervention would permit the quantification, utilization of statistical techniques and benefits, due to the solution of different kind of problems.

\subsection{Design and implementation}

The process of the D-PIP design and implementation is presented in Figure 6 . It considers, additionally to the type of M-SME, based on different evaluation of results made by II-UNAM, the level of stakeholder participation, duration of the service and its intensity. See Figure 5.

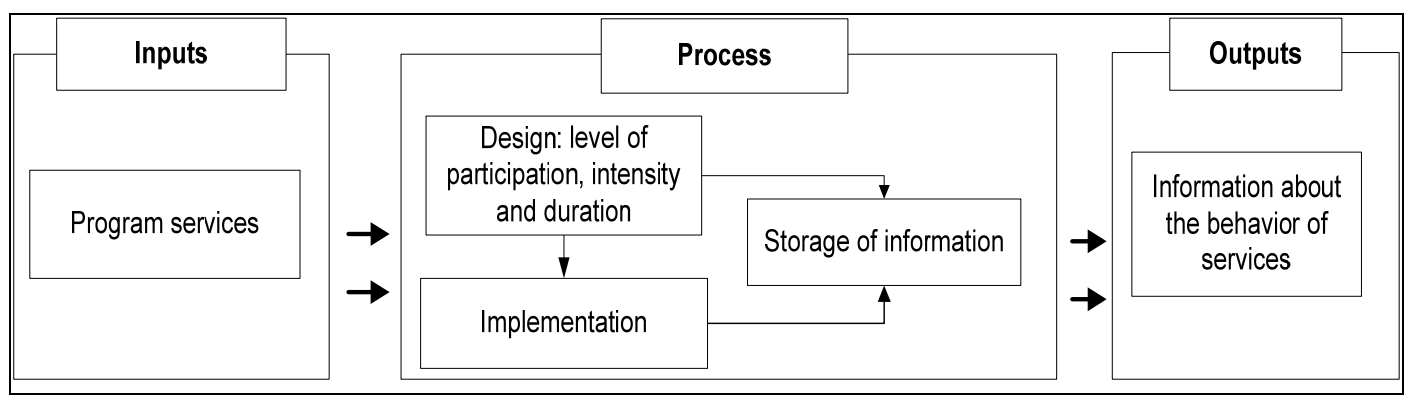

Figure 4. Program services design and implementation. 


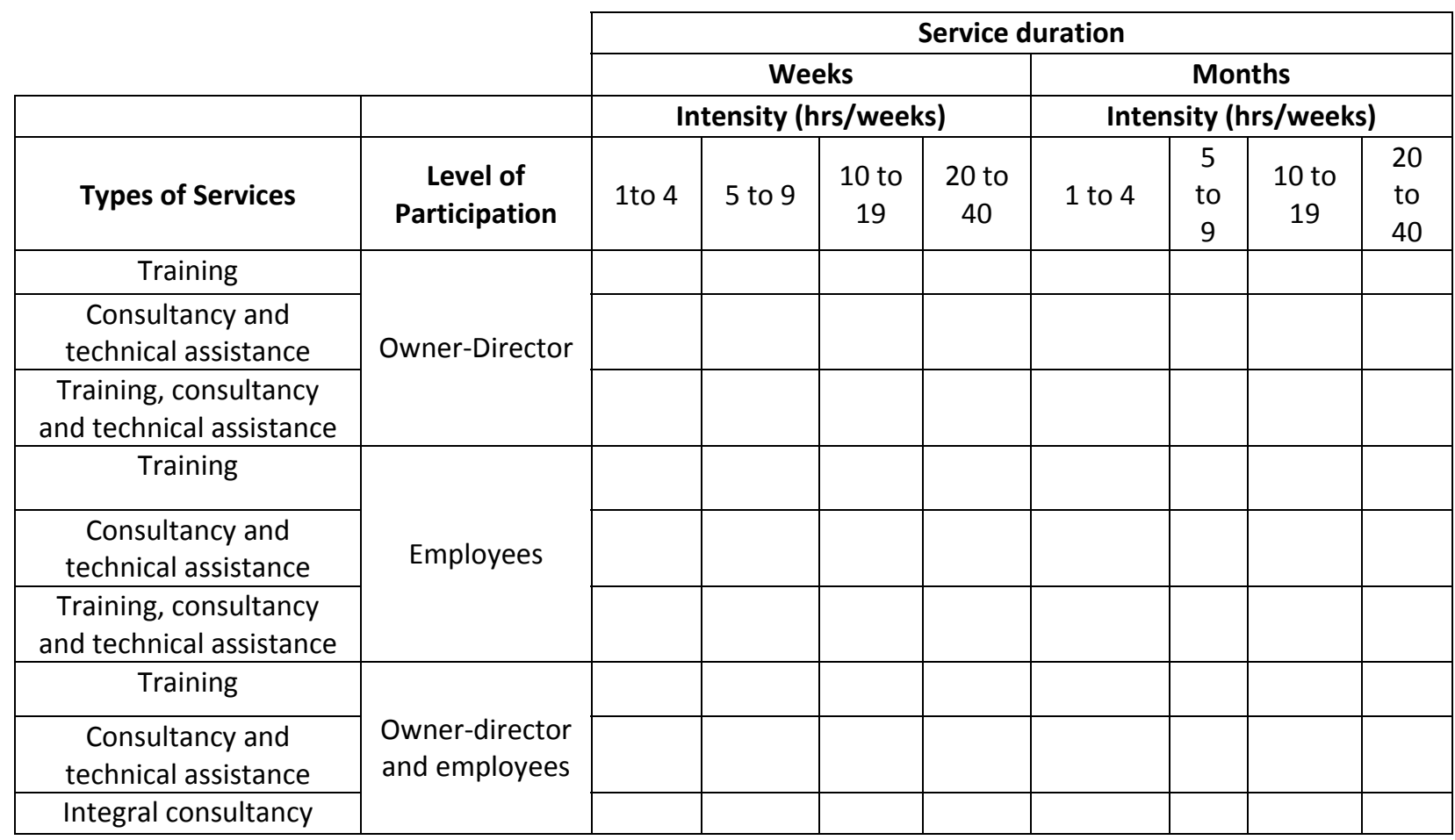

Table 1. Factors to consider in the design of a D-PIP.

The services design must analyze the relation between the following factors: the level of participation, duration and intensity, (see Table 1). The existent relationship among them depends on what each service tries to achieve inside M-SME.

- Service duration. The period of time in which the service is carried out. It is quantified from the $M$ SME acceptation to be intervened, to the finishing of the service. The measuring unit could be days, weeks or months. It depends on the complexity of the problems that services have to solve and the availability of time of the firms to be intervened.

-Intensity. Weekly hours assigned to do activities agreed by the service and M-SME.

- Level of participation. Corresponding to the stakeholders who must participate during the intervention process. For example, ownermanager, employees or both. It depends on the service purpose.

Previous to the implementation, it is necessary to identify the economical and human resources, infrastructure and other inputs in order to carry out every service and establish the goals. During the implementation, the services must collect data and storage it in a computer system.

\subsection{Evaluation of results}

The purpose of this stage is to measure the efficacy of services and the productive efficiency of M-SME intervened, following the process presented in Figure 6 . This evaluation is focused on quantifying the benefits generated in every firm, such as M-SME. Firstly, how much the firm increases their productivity and secondly what kind of problems the enterprise solves with their own resources as well as the identification of the problems that were not solved and the new problems that appear as a consequence of the solution of previous obstacles. It is also necessary to verify the information gathered by the consultants in order to make better decisions. 


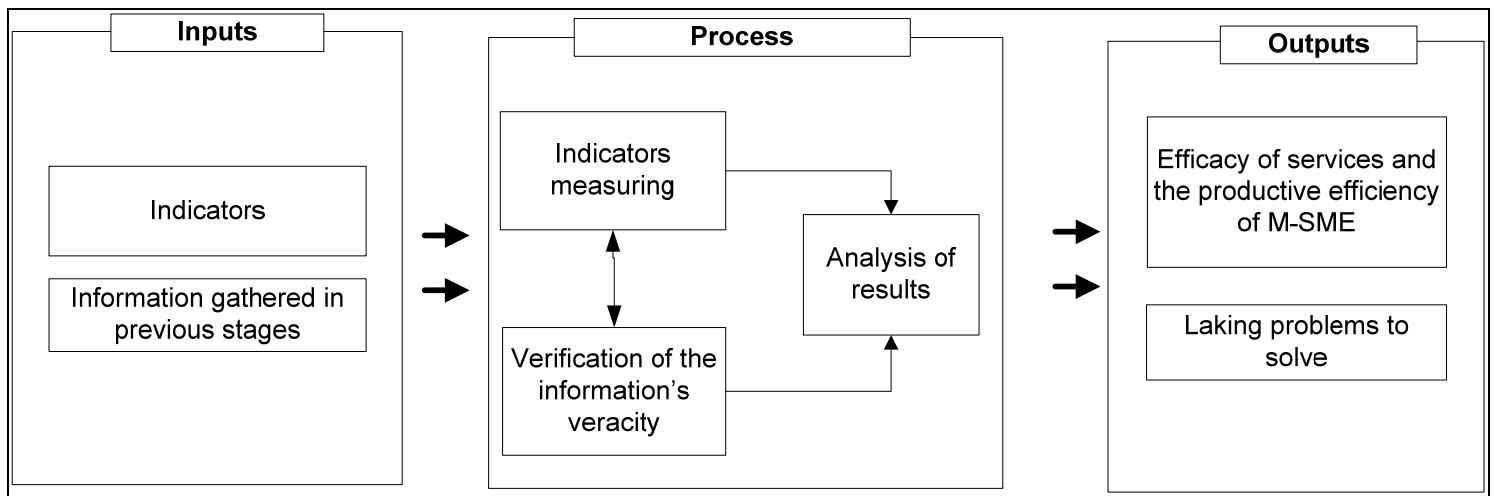

Figure 6. Evaluation of services.

The evaluation of efficacy services is necessary before the use of discriminatory functions obtained through the discriminate analysis. These sorts of functions classify the intervened firm in one group of M-SME based on the level of the growth.

\section{A Mexican successful case}

The model described has been closely followed by PRW and has been improved in terms of duration of time (it has been improved in base to some of the II-UNAM suggestions).

\subsection{Processes Reengineering Workshop}

Although the PRW is not the only service that NCPTI offers to the Mexican national industry, it is the main structure used by the program to design most of its services. It is with this service that NCPTI began to operate. The main objective of PRW is to improve the productivity of Mexican MSME. At present day, it is considered a successful outcome by different evaluations carried out by the II-UNAM [6]. The evaluations' highlights show that the service is highly accepted by the owners of the firms due to the fact that M-SME productivity has increased $37 \%$ on average, according to the entrepreneurs.
The model helps identify and solve production processes problems, considering only the resources available for the firm when is intervened by the workshop. It includes the participation of the owner of the firm and workers, from the beginning to the end of the intervention. To identify the problems and their solution, the workshop basically uses brainstorming technique to share the stakeholders' perceptions and expertise.

PRW is constituted by the following phases: analysis of the production process and identification of the problems, feasibility analysis of the latter and measurement of predefined performance indicators, carrying out improvement actions and lastly measurement of performance indicators after the intervention. This model, as shown in Figure 7, is similar to the one proposed by Nexus. So it is very likely that the PRW's success results from following each of the phases of a Deming cycle which has considered the participation of the owner-director of the firm and the ones involved in the transformation processes.

From 1998 to 2002, there were 3,545 firms directly benefited by PRW, where $51 \%$ are classified as small firms (11-50 employee), $29 \%$ as micros (1-10 employee), $17 \%$ as mediums (51-250 


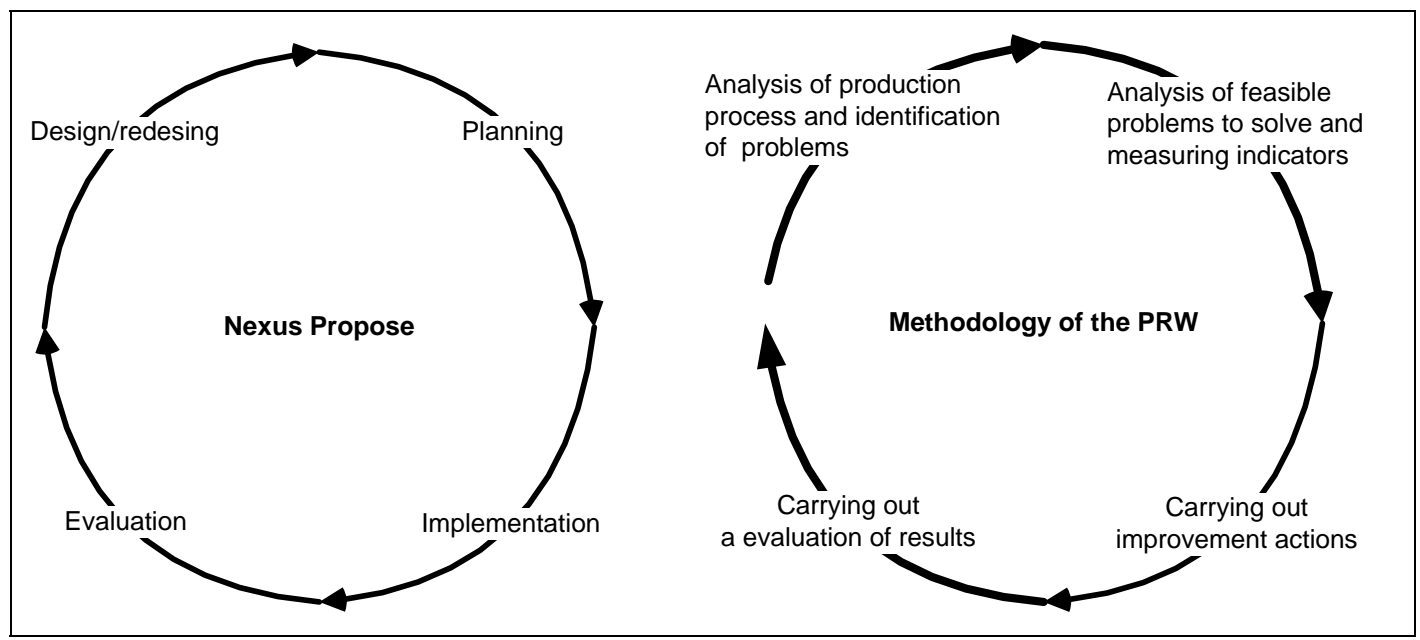

Figure 7. The structure proposed by Nexus and the PRW methodology.

employee), and the rest as big firms. All of them belong to the industrial sector. We include only this period because the information analysis used to build the taxonomy of M-SME corresponds to these years.

According to II-UNAM evaluations, the ownersmanagers of the firms recognize and validate the benefits generated by PRW; however, the productivity of M-SME decreases after certain time. This happens because the organizations fall into operating transformation processes as they used to in the past.

Another claim made by owners-managers is that the PRW design does not consider the heterogeneity of M-SME. In some cases, they argue the workshop does not fulfill their expectancies as they would hope it would solve other problems. This perception diminishes when in one of the phases of PRW, which considers the elaboration of a diagnosis, production processes problems are identified.

The diagnosis has allowed the identification of problems in the enterprises processes by everyone who intervenes in the firm; ownersmanagers and the workforce. If we analyze this kind of information, like the II-UNAM did; NCPTI would design differentiated services and new programs that contribute to the organizational development of the firms and NCPTI could be in a continuous improvement process. This explanation is represented in the last figure as a gap, between the steps "Analysis of the transformation process and identification of problems" and "Implementation of improvement actions".

However, it does not consider the M-SME differentiation and does not evaluate the efficacy for every service.

\subsection{A way to differentiate the NCPTI services}

Based on the PRW information analysis, we identify the necessity to address the services toward specific groups of firms, classified according to their production processes problems and the level of growth of the firms. 
According to López et al. [7] and Bautista [8] the classification process is constituted by three phases. The first one clusters problems, the second one associates the problem groups to specific types of firm (a priori classification), the last one verifies statistically the significant differences between groups of M-SME.

The analysis was focused on 3,545 firms benefited by PRW. The findings show that M-SME commonly identifies 36 internal problems. All of them were grouped through the cluster analysis statistic technique. The identified groups of problems in the transformation processes are

-Group 1. Problems associated to production planning. These problems are related to how the production process is organized. Stakeholders identify this kind of problems when they know the operation of production process and have enough control of it.

-Group 2. Problems associated to technical operation. They are generated when the stakeholders do not know the way in which the production process operates and the sort of inputs which are necessary for its correct operation.
-Group 3. Problems associated to management and control of processes. These problems happen when the firms begin to recognize that explicit knowledge is important to improve the production processes and, on this premise, it is possible to make better decisions. It also refers to cases in which the human capital wants to improve their quality of life in the work place.

- Group 4. Problems associated to security and maintenance. These problems exist when the work place, installations and tools do not receive enough maintenance or there is a lack of measures of security.

- Group 5. Others which have different subgroups of problems; some of them are associated with workforce rotation, inappropriate materials, design of product, customer service (post selling) and lack of workforce, which could be related to firms concerned with the relationship between the organization and their environment.

Every group of problems was linked to the Albino et al. [9] taxonomy. This activity was done in two stages: in the first one, the groups of problems were associated to every type of firm in a priori form as shown in Table 2.

\begin{tabular}{|l|ll|}
\hline \multicolumn{1}{|c|}{ Type of M-SME } & & \multicolumn{1}{c|}{ Group of Problems } \\
\hline Level 1. Imitative & - & Associated to the technical domination \\
\hline Level 2. Tacit & - & Associated to production planning \\
& - Associated to direction and dominium of the process \\
& - & Associated to security and maintenance \\
\hline Level 3. Qualitative & - & Other \\
\hline
\end{tabular}

Table 2. Groups of problems associated to type of firm. 
In the second stage, using the discriminant analysis, we validated the a priori classification. It allowed corroborating with contrasting discriminate functions, through Wilks Lambda equal to 0.234 and a significance level less than 0.005 , that there are significant differences between M-SME groups. Figure 8 clearly shows three M-SME groups with separated centroids.

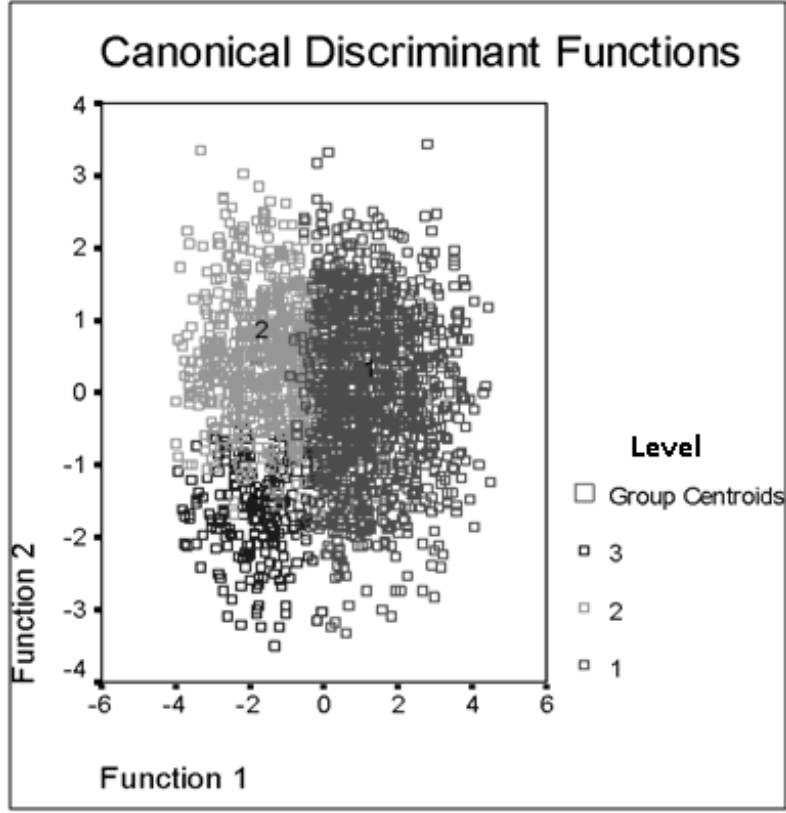

Figure 8. M-SME groups confirmed throughout the discriminant analysis.
In Mexico, it is common for programs to be addressed by the M-SME size, specifically by the number of the enterprise's employees; at least, this is the common suggestion that experts have made. However, contrasting the three types of firms (intuitive, tacit and qualitative) against the size based on the number of employees, it was possible to identify that there are similar percentages of firms classified by size in every type of M-SME. Evidences are shown in Table 2.

This allows the argument that the size of the firms is not the principal feature that determines the behavior of organizations, just as happens with the level of growth of the firms. For this reason, PIP must be differentiated by the level of growth of the firms, in particular, for M-SME.

\section{Conclusions and suggestions}

When a PIP follows the Deming's phases, it achieves a high level of acceptance by ownermanager and employees, due to the fact that $\mathrm{M}$ SME have the possibility of reaching a high level of productivity through the solution of problems related to production processes. Particularly, PRW and NCPTI are evidence of this behavior, considered successful Mexican cases.

\begin{tabular}{|c|c|c|c|}
\hline Size of firm & Intuitive (\%) & Tacit (\%) & Qualitative (\%) \\
\hline Micro (less than 10 employees) & 55.75 & 30.00 & 14.25 \\
\hline Small (less than 50 employees) & 56.79 & 33.82 & 9.40 \\
\hline Medium (less than 250 employees) & 61.98 & 30.37 & 7.65 \\
\hline Total & 57.61 & 32.39 & 10.00 \\
\hline
\end{tabular}

Table 3. Firms analyzed with discriminate analysis by size and level of growth. 
Some strengths of PRW are that it follows the Deming Cycle and it includes the owner-manager and the workforce participation during the intervention process. Therefore, these stakeholders are able to identify problems, suggest, agree on solutions and carry them out. This way, the integration of different perspectives can be considered as another advantage of PRW. However, if the program does not analyze the experience of the stakeholders, it might be complicated to reach a continuous improvement process, as happened with this service.

To complete the Deming Cycle in the PRW case, we suggest that the program design must be differentiated by the level of growth of M-SME.
The evidence that was gathered by PRW shows that M-SME could be divided into three groups of firms: imitative, tacit and qualitative.

The groups of M-SME allow the development of a model implemented to design differentiated PIP. This method offers different advantages, firstly, being in a continuous improvement process according to the internal problems of M-SME and, secondly, it allows quantifying the efficacy of programs, measuring the level of growth of $\mathrm{M}$ SME and the efficiency evaluating the productive improvement of the type of firms intervened.

Finally, we recommend different methods used for a variety of purposes, including planning, structuring, and improvement (see Table 4), that PIP must structure and implement to benefit MSME.

\begin{tabular}{|c|c|c|c|c|c|}
\hline \multirow{2}{*}{ Methods } & \multirow{2}{*}{ Stakeholders } & \multirow{2}{*}{$\begin{array}{l}\text { Duration } \\
\text { (days) }\end{array}$} & \multicolumn{3}{|c|}{ Type of M-SME } \\
\hline & & & Imitative & Tacit & Cualitative \\
\hline Conceptual map & ho, he & $1-3$ & $\sqrt{ }$ & $\sqrt{ }$ & $\sqrt{ }$ \\
\hline Solution to problems & ho & $2-5$ & $\sqrt{ }$ & $\sqrt{ }$ & \\
\hline Cause and effect & ho & $3-5$ & $\sqrt{ }$ & $\sqrt{ }$ & $\sqrt{ }$ \\
\hline Analysis KT & ho & $3-5$ & & $\sqrt{ }$ & \\
\hline $\begin{array}{c}\text { Group communication } \\
\text { network }\end{array}$ & ho & $1-2$ & & $\sqrt{ }$ & $\sqrt{ }$ \\
\hline TKJ technique & ho, he & $2-3$ & $\sqrt{ }$ & $\sqrt{ }$ & $\sqrt{ }$ \\
\hline TOWS matrix & ho & 7 & & & $\sqrt{ }$ \\
\hline Idealized design & ho, he & 7 & & & $\sqrt{ }$ \\
\hline Morphological analysis & ho, he & 7 & & & $\sqrt{ }$ \\
\hline $\begin{array}{c}\text { Nominal Group } \\
\text { Technique }\end{array}$ & ho, he & $1-2$ & & $\sqrt{ }$ & $\sqrt{ }$ \\
\hline Cross Impact Method & ho & 20 & & & $\sqrt{ }$ \\
\hline Scenarios & ho, he & 60 & & & $\sqrt{ }$ \\
\hline Analytical hierarchy & ho & 15 & & & $\sqrt{ }$ \\
\hline Evaluation Matrix & ho, he & $1-2$ & $\sqrt{ }$ & $\sqrt{ }$ & $\sqrt{ }$ \\
\hline Planning meeting & he & $2-4$ & & & $\sqrt{ }$ \\
\hline
\end{tabular}

Note: ho: homogeneous; he: heterogeneous This table was built in base to Sánchez [10].

Table 4. Methods to promote the development according to the type of M-SME. 


\section{A model to design effective Production Improvement Programs, T. Bautista et al., 72-86}

\section{References}

[1] ICP (Comisión Intersecretarial de Política Industria, 2003). Observatorio PyME México. Primer reporte de resultados 2002. 5 January 2006 < http://www.cipi.gob.mx/html/reporteanalitico.pdf >

[2] Nexus Associates, 1999. Componente I. Definición de un Sistema permanente para determinar las necesidades prioritarias de las MPyMEs en México. CIPI - BANCO MUNDIAL. 25 April 2005 < http://www.cipi.gob.mx/html/principal.html>

[3] Huang, Tun Chun, 2001. The relation of training practices and organizational performance in small and medium enterprises. Education and training. Vol. 43, pp. 437-443.

[4] UNIDO (The United Nations Industrial Development Organization, UNIDO, 2004). 15 May 2004 < http://www.unido.org/doc/5066\#IndustrialDiagnosis>

[5] Hernández, Ulises, 2007. Programas en pausa. Expansión, Julio, 9 pp. 76-77. México.

[6] II-UNAM, 2003, 2004, 2005, 2006, 2007. Informe definitivo. Evaluación de Consistencia y Resultados y Diseño de COMPITE. México. 7 March 2007 < http://www.compite.org.mx/principal/reglasoperacion/ eunam.asp>

[7] López O., E., Bautista, G. T., Canales S., D., Briceño, V., S. Principales problemas operativos en las empresas industriales en México. Aplicación del análisis de conglomerados. Publicado en las memorias del VI Seminario Internacional de Ingeniería de Sistemas. Soluciones Innovadoras para la Gestión de Recursos y la Toma de Decisiones. Noviembre de 2006.

[8] Bautista G., T., 2009. Una propuesta metodológica para diseñar programas de mejora productiva eficaces. Tesis doctoral. Facultad de Ingeniería de la UNAM.

[9] Albino V., Garavelli, A.C., Schiuma, G., 2001. Knowledge transfer and inter-firm relationships in industrial districts: the role of the leader firm. Technovation 19, 53-63.
[10] Sánchez G., G.N., 2003. Técnicas participativas para la planeación, FICA, México.

\section{Acknowledgments}

The present paper is part of a research project carried out by the Instituto de Ingeniería of the UNAM, financed by NCPTI.

We express our gratitude to the referees who provided suggestions and comments to improve this article. 


\section{Authors' Biography}

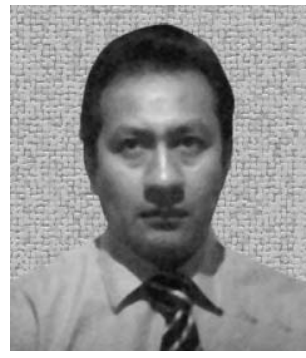

\section{Tomás BAUTISTA}

He received a Ph.D. degree in system engineering, specifically in planning, from Universidad Nacional Autónoma de México (UNAM), Mexico. He is a professor in the postgraduate Program of Engineering (systems and planning) of the UNAM. He is also a professor of bussines major courses in the Instituto Tecnológico y de Estudios Superiores de Monterrey, Campus Ciudad de México, (ITESM-CCM), Mexico. He has been researching in the design productive improvement programs, using the Systems Approach Theory. He is an expert in organizational development and the Information and Communication Technology acceptance issue. He has evaluated governmental productive improvement programs to measure the benefits that generate in the small and medium-sized enterprises.

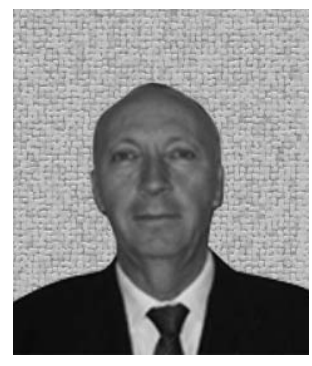

\section{Eugenio Mario LÓPEZ-ORTEGA}

He is a researcher at Institute of Engineering of the Universidad Nacional Autónoma de Mexico (UNAM). He received his MSc degree in engineering from the UNAM. He leads the Industrial and Technological Systems Group at the Institute of Engineering-UNAM. This Group has carried out several projects related to problem-identification at the small and medium enterprises (SME) in Mexico. Since 2001, the group has collaborated with COMPITE (National Committee for Productivity and Technology Innovation).

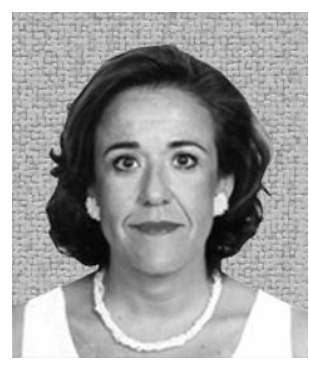

\section{Judith ZUBIETA}

She is a full researcher at the UNAM's Institute for Social Research, she got her Ph.D. degree from Wharton's Social System Sciences Program. She is also a professor at the Graduate Programs of Management and Engineering (Systems and Planning). Author of numerous scientific publications and specialized texts, she has also developed a strong career in scientific diffusion, chairing programs devoted to attract young students into science and technology. Her research areas of interest are Mexico's innovation system, mathematical modeling of social issues, and systems planning. She is an active member of the Mexican Academy of Sciences and participates in the National System of Researchers (level II). In recognition of her work and commitment, she has been posted for high top positions within UNAM as well as in the Federal Government. 


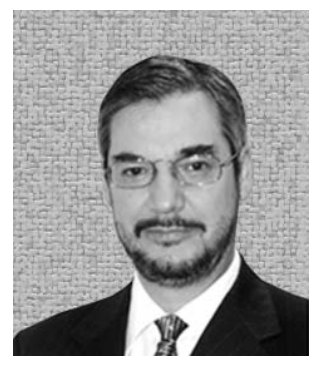

\section{Santiago MACÍAS}

Santiago Macías is an electrical mechanical engineer with a master's degree in operations research from UNAM. He is also a businessman, public official, researcher at the Institute of Engineering, professor at the Faculty of Engineering of UNAM and at the Division of Higher Studies of ITAM, visiting professor of ITESM and of the World Trade University in New York, counselor of institutions such as NAFIN, BANCOMEXT, FINASA, PEMEX, National Railways, FONACOT, representative of Mexico in the Committee of Consumer Protection of the OECD and the Convention of collaboration between Mexico and the SBA of US, and reviewer for the National Prize for Exports. He has published several articles in national and international publications on topics such as planning, regional development, competitiveness of small and medium-sized enterprises and consumer protection and has been a lecturer at national and international forums. Now, he is the general coordinator of the COMPITE Civil Association. 